\title{
Factors Associated with Nosocomial Infection in the Elderly in the Intensive Care Unit

\begin{abstract}
Laelson Rochelle Milanês Sousa1, Luana Kelle Batista Moura², Maria Eliete Batista Moura², Glícia Cardoso Nascimento ${ }^{4}$, Francisca Tereza Coelho Matos ${ }^{5}$, Thiago Lima Monte ${ }^{5}$
\end{abstract}

\section{Abstract}

Background: The elderly have increased vulnerability to disease and exposure to hospital infections.

Aims: The study aims to evaluate the clinical and epidemiological factors associated with nosocomial infection in the elderly.

Methods: A retrospective study with a population of 625 elderly patients admitted to intensive care units and a sample of 308 elderly who developed nosocomial infection from January 2012 to June 2015.

Results: A total of $49.7 \%$ of the elderly presented a growth of micro-organisms in tracheal aspirates. The diseases classified as "other" increased likelihood of tracheal infection $(3.61,95 \%-\mathrm{Cl} 1.84$ to 7.10; $p=0.005)$ and the probability of growth of micro-organism in the culture performed elsewhere - general $(8.96,95 \%-\mathrm{Cl} 3.03$ to 26.49; $p=0.005)$. Surgical procedures increased the chance of growth of micro-organisms in tracheal secretion culture (OR 1.96, $95 \% \mathrm{Cl} 1.11$ to 3.48 ) and surgical site culture (OR 5.06, 95\% Cl 1, from 76 to 14.55). The neurological disease increased the chance of growth of micro-organisms in the cultures of tracheal secretions, blood and general (OR 3.80, 95\% Cl 1.22 to 11.83; OR 3.27, 95\% $\mathrm{Cl} 1.24$ - 8.66; OR $15.61,95 \% \mathrm{Cl} 4.78$ to 50.98). The pneumothorax increases by four times the probability of growth of micro-organisms in the catheter tip (OR 4.17,95\% Cl 1.24 to 13.97). Chronic and acute renal failure and other diagnoses increased by eighteen times the chance of growth of micro-organisms in general culture (OR 18.06, $95 \% \mathrm{Cl} 3.63$ to 89.86$)$.
1 Nurse. Post Graduation Program in Nursing, Federal University Piauí, UFPI, Teresina, Piauí, Brazil.

2 Dentist. Doctor. Post Graduation Program, Professional Masters in the Family Health, University Center UNINOVAFAPI, Teresina, Piauí, Brasil.

3 Nurse. Doctor. Post Graduation Program in Nursing, Federal University Piauí, UFPI, Teresina, Piauí, Brazil.

4 Nursing graduate. Federal University Piauí, UFPI, Teresina, Piauí, Brasil.

5 Dentist. Doctor. Department of Dentistry, University Center UNINOVAFAPI, Teresina, Piauí, Brasil.

\section{Contact information:}

Laelson Rochelle Milanês Sousa.

Address: Ininga, 64.049-550. Teresina, PI, Brazil.

Tel: +55 86 98161-5992.

Đlaelson_@hotmail.com 
Conclusion: The main risk factors for nosocomial infection of elderly in the Intensive Care Unit are chronic and acute renal failure, neurological diseases and surgical procedures and must be adopted a policy of prevention and control of nosocomial infection in the treatment of the elderly.

\section{Keywords}

Elderly, Cross infection, Intensive Care.

\section{Introduction}

In Brazil, the number of elderly is increasing. In the Piauí, northeastern state of Brazil, this percentage reaches $11.4 \%$ of the population, a number considered very significant [1]. This increase is already perceived in health institutions, especially in critical sectors. In Intensive Care Units (ICU), the number of assisted elderly has increased in recent decades. Among the diseases that threaten the safety of the elderly in this environment stands out the nosocomial infection in age extremes, by intrinsic factors such as advanced age and associated comorbidities and extrinsic factors such as hospital environment, main diagnosis and the presence of events adverse. It can be seen in the literature a large focus on studies related to nosocomial infection in newborns, however there is a huge failure when it comes to the elderly population, especially in developing countries.

About $42-52 \%$ of patients admitted in Brazilian ICUs are elderly, holding about $60 \%$ of hospital daily available in this environment, in addition, high portion of these individuals progress to death [2].

The study is justified by the nosocomial infection (NI) in Brazil show up as a growing problem with consequences that include increased in expenditures, in the patient's hospital stay and the increase in mortality rates, especially among the elderly. The study aims to evaluate the clinical and epidemiological factors associated with nosocomial infection in the elderly in the Intensive Care Unit.

\section{Methodos}

This is a retrospective descriptive study of prevalence, performed in adult intensive care unit of a large general hospital, reference in the northeastern of Brazil. This hospital performs more than 200,000 annual consultations and provides medical and surgical care in various specialties, acting as rearguard for all through the middle northern region of Brazil.

The population of the study included 625 elderly patients hospitalized in the health service's ICU investigated from January 2012 to June 2015, with a diagnosis of hospital infections, according to the criteria of the Center of Disease Control and Prevention - CDC confirmed by bacterial culture.

The sample consisted of 308 elderly patients (60 years or older) who developed nosocomial infection during the period surveyed. The mean length of stay in the ICU is 73.5 (seventy-three and a half) patients/month, most of them for neurological and cardiac causes or postoperative of major surgeries.

Data collection took place in records of the Hospital Infection Control Commission database, supplemented by information acquired in the billing sector and the Medical Records and Statistics Service. The instrument was a structured questionnaire with information regarding sociodemographic conditions (gender, age, nationality and profession), the topography of the infection, pre-existing diseases and the main diagnosis for hospitalization.

Data were entered in Excel 2010 program in double entry and validation, and analyzed using the Statistical Package application for Social Sciences (SPSS) version 20.0. 
For verification association between hospital infection and the study variables, the prevalence ratios and odds ratios, (multivariate analysis of binary outcome parameters were realised by logistic regression and visualized by showing related odds ratios with 95\% confidence intervals), Fisher's exact test and chi-square test were calculated. The most significant data were presented in tables and graphs.

\section{Results}

The nosocomial infection reached the elderly aged 60-97 years with a mean age of 68.28 years. were predominantly female (68\%), and marital status married (64\%). The prevalence of nosocomial infection in elderly patients was $42.8 \%$.

The study results show the relationship of gender, age, nationality, profession, pre-existing diseases and diagnosis of hospitalized elderly in the Intensive Care Unit with the results of cultures made. Almost half of the elderly presented a growth of microorganisms in the tracheal secretions (47.7\%), while in the urine, this growth was observed in approximately one third of the elderly (33.8\%) and in the blood (21.1\%). Statistically significant difference was identified between sex, age and original hospital (countryside of state, central hospital, or originating in other states) (Table 1).

Different pre-existing conditions were analyzed according to whether they are risk factors for the growth of micro-organisms in bacterial cultures. The diseases classified as "other" increased approximately three and a half times the probability of growth of micro-organisms in bacterial culture performed in the tracheal secretion, and approximately nine times the likelihood of this growth culture performed in other locations (general), and has significant influence on the decrease of cases in which a growth of microorganisms in the catheter tip culture.

The presence of more than a pre-existing comorbidity has increased by approximately eight and a half times the chance of growth of micro-organisms in culture of surgical site infections and general culture (Table 2).

Table 1. Distribution of elderly who had positive bacterial culture, according to the variables: sex, age, nationality and profession.

\begin{tabular}{|c|c|c|c|c|c|c|c|c|}
\hline \multicolumn{9}{|c|}{ Topography of infections } \\
\hline \multirow{3}{*}{$\begin{array}{c}\text { Sociodemographic } \\
\text { Variables }\end{array}$} & \multicolumn{7}{|c|}{ Bacterial Culture } & \multirow{3}{*}{ p-valor* } \\
\hline & $\begin{array}{l}\text { Tracheal } \\
\text { secretions }\end{array}$ & Urine & Blood & Catheter Tip & $\begin{array}{l}\text { Surgical } \\
\text { Wound }\end{array}$ & $\begin{array}{l}\text { Surgical site } \\
\text { infection }\end{array}$ & $\begin{array}{l}\text { General } \\
\text { Culture* }\end{array}$ & \\
\hline & $\%$ & $\%$ & $\%$ & $\%$ & $\%$ & $\%$ & $\%$ & \\
\hline \multicolumn{9}{|l|}{ Sex } \\
\hline Men & 55.9 & 31.5 & 24.4 & 5.5 & 3.1 & 3.9 & 7.1 & \multirow{2}{*}{0.046} \\
\hline Women & 45.3 & 35.4 & 18.8 & 9.4 & 8.8 & 5.5 & 3.3 & \\
\hline \multicolumn{9}{|l|}{ Age } \\
\hline 60 to 69 years & 49.4 & 34.0 & 18.6 & 6.4 & 7.7 & 6.4 & 5.1 & \multirow{3}{*}{0.019} \\
\hline 70 to 79 years & 46.3 & 29.5 & 25.3 & 13.7 & 5.3 & 3.2 & 5.3 & \\
\hline 80 or older & 56.1 & 40.4 & 21.1 & 1.8 & 5.3 & 3.5 & 3.5 & \\
\hline \multicolumn{9}{|l|}{ Originating From } \\
\hline Countryside of State & 46.0 & 37.3 & 20.7 & 4.7 & 8.0 & 2.7 & 4.0 & \multirow{3}{*}{0.004} \\
\hline Capital of State & 55.4 & 34.8 & 17.0 & 7.1 & 2.7 & 6.3 & 2.7 & \\
\hline Other states & 47.8 & 19.6 & 32.6 & 19.6 & 10.9 & 8.7 & 13.0 & \\
\hline Total & 49.7 & 33.8 & 21.1 & 7.8 & 6.5 & 4.9 & 4.9 & \\
\hline
\end{tabular}


Table 2. Distribution of preexisting comorbidities of the elderly and the topography of infections according to the odds ratio test and Fisher's exact test.

\begin{tabular}{|c|c|c|c|c|c|c|c|}
\hline \multirow[b]{2}{*}{ Variables } & \multicolumn{7}{|c|}{ Topography of infections } \\
\hline & $\begin{array}{l}\text { Tracheal } \\
\text { secretions }\end{array}$ & Urine & Blood & $\begin{array}{l}\text { Surgical } \\
\text { Wound }\end{array}$ & $\begin{array}{l}\text { Surgical site } \\
\text { infection }\end{array}$ & Catheter tip & $\begin{array}{l}\text { General } \\
\text { Culture* }^{*}\end{array}$ \\
\hline \multicolumn{8}{|l|}{ Pre-existing diseases } \\
\hline \multirow{2}{*}{ Hypertension } & 1.05 & $0.85(1.18)$ & $0.92(1.09)$ & 1.80 & $0.51(1.96)$ & $0.69(1.45)$ & $0.14(7.14)$ \\
\hline & {$[0.65: 1.69]$} & {$[0.51: 1.42]$} & {$[0.51: 1.67]$} & {$[0.72: 4.50]$} & {$[0.14: 1.86]$} & {$[0.26: 1.78]$} & {$[0.02: 1.10]$} \\
\hline \multirow{2}{*}{ CRF/ARF** } & $0.64(1.56)$ & 1.16 & $0.79(1.27)$ & 0.91 & $0.25(4.00)$ & 2.39 & - \\
\hline & [0.37: 1.11] & {$[0.66: 2.04]$} & {$[0.40: 1.59]$} & {$[0.29: 2.82]$} & {$[0.03: 1.94]$} & {$[1.00: 5.74]$} & 0.05 \\
\hline \multirow{2}{*}{$\begin{array}{l}\text { Other pre-existing } \\
\text { comorbidities }\end{array}$} & 3.61 & 1.62 & 1.18 & - & 1.28 & - & 8.96 \\
\hline & {$[1.84: 7.10]$} & [0.88: 2.99] & {$[0.58: 2.42]$} & 0.06 & {$[0.35: 4.69]$} & 0.02 & [3.03: 26.49] \\
\hline \multirow{2}{*}{ Diabetes } & $0.80(1.25)$ & $0.67(1.49)$ & 1.19 & 1.87 & - & 3.36 & - \\
\hline & {$[0.40: 1.58]$} & {$[0.31: 1.44]$} & {$[0.53: 2.65]$} & {$[0.59: 5.91]$} & 0.23 & {$[1.29: 8.74]$} & 0.23 \\
\hline \multirow{2}{*}{$\begin{array}{l}\text { More than one } \\
\text { comorbidity }\end{array}$} & $0.48(2.08)$ & 1.52 & $0.61(1.64)$ & 1.57 & 8.66 & - & 8.66 \\
\hline & [0.19:1.23] & {$[0.62: 3.72]$} & {$[0.17: 2.12]$} & {$[0.34: 7.29]$} & [2.65: 28.34] & 0.39 & [2.65: 28.34] \\
\hline \multirow{2}{*}{ Cardiac disorders } & $0.80(1.25)$ & $0.98(1.02)$ & 1.96 & - & - & $0.68(1.47)$ & - \\
\hline & {$[0.31: 2.01]$} & {$[0.36: 2.69]$} & {$[0.71: 5.43]$} & 0.62 & 1.00 & [0.09: 5.37] & 1.00 \\
\hline \multirow{2}{*}{ Obesity } & 1.01 & $0.38(2.63)$ & 1.26 & 1.33 & - & 1.08 & - \\
\hline & {$[0.32: 3.22]$} & {$[0.08: 1.77]$} & {$[0.33: 4.79]$} & [0.16:10.82] & 1.00 & [0.13:8.73] & 1.00 \\
\hline
\end{tabular}

*: Cultures that do not allow exact isolation of a single pathogen. **: Renal Infection Chronic and Acute Renal Failure.

Surgical procedures increased by approximately twice the chance of growth of microorganisms in the culture of tracheal secretions and five times in the surgical site infection. The neurological disease increased the chance of growth of micro-organisms in the cultures of tracheal secretions, blood and in general, about four, three and fifteen and a half times, respectively. Finally, both acute kidney failure and other diagnoses increased in eighteen times the chance of growth of micro-organisms in the overall culture. (Table 3)

Table 3. Distribution of diagnosis of the elderly and the topography of infections according to the odds ratio and Fisher exact tests.

\begin{tabular}{|c|c|c|c|c|c|c|c|}
\hline \multirow[b]{2}{*}{ Variables } & \multicolumn{7}{|c|}{ Topography of infections } \\
\hline & $\begin{array}{l}\text { Tracheal } \\
\text { secretions }\end{array}$ & Urine & Blood & $\begin{array}{l}\text { Surgical } \\
\text { wound }\end{array}$ & $\begin{array}{l}\text { Surgical site } \\
\text { infections }\end{array}$ & Catheter tip & $\begin{array}{l}\text { General } \\
\text { culture* }^{*}\end{array}$ \\
\hline \multicolumn{8}{|l|}{ Pre-existing diseases } \\
\hline \multirow{2}{*}{ Members Fracture } & 1.10 & 1.23 & $0.83(1.20)$ & $0.41(2.44)$ & - & 2.04 & $0.26(3.85)$ \\
\hline & {$[0.63: 1.91]$} & {$[0.69: 2.18]$} & {$[0.41: 1.67]$} & {$[0.09: 1.79]$} & 0.05 & {$[0.83: 5.00]$} & {$[0.03: 2.02]$} \\
\hline \multirow{2}{*}{ Surgical procedures } & 1.96 & 1.01 & $0.87(1.15)$ & 1.77 & 5.06 & $0.34(2.94)$ & $0.60(1.67)$ \\
\hline & {$[1.11: 3.48]$} & {$[0.56: 1.81]$} & {$[0.43: 1.76]$} & {$[0.65: 4.83]$} & {$[1.76: 14.55]$} & {$[0.08: 1.48]$} & {$[0.13: 2.72]$} \\
\hline \multirow{2}{*}{ Neurological Trauma } & $0.51(1.96)$ & $0.66(1.52)$ & 1.44 & 2.20 & - & 1.68 & - \\
\hline & {$[0.27: 0.93]$} & {$[0.34: 1.28]$} & {$[0.73: 2.84]$} & {$[0.80: 6.01]$} & 0.08 & {$[0.63: 4.46]$} & 0.08 \\
\hline \multirow{2}{*}{ Liver's disease } & 1.02 & 1.47 & $0.90(1.11)$ & 1.46 & $0.39(2.56)$ & $0.23(4.35)$ & - \\
\hline & {$[0.54: 1.90]$} & {$[0.77: 2.78]$} & {$[0.41: 1.96]$} & {$[0.47: 4.59]$} & {$[0.05: 3.07]$} & {$[0.03: 1.75]$} & 0.14 \\
\hline \multirow{2}{*}{ Cardiovascular's disease } & $0.68(1.47)$ & $0.57(1.75)$ & $0.97(1.03)$ & - & 2.11 & 1.17 & - \\
\hline & {$[0.33: 1.40]$} & {$[0.25: 1.31]$} & {$[0.40: 2.33]$} & 0.14 & {$[0.57: 7.90]$} & {$[0.33: 4.14]$} & 0.39 \\
\hline
\end{tabular}




\begin{tabular}{|c|c|c|c|c|c|c|c|}
\hline \multirow[b]{2}{*}{ Variables } & \multicolumn{7}{|c|}{ Topography of infections } \\
\hline & $\begin{array}{l}\text { Tracheal } \\
\text { secretions }\end{array}$ & Urine & Blood & $\begin{array}{l}\text { Surgical } \\
\text { wound }\end{array}$ & $\begin{array}{l}\text { Surgical site } \\
\text { infections }\end{array}$ & Catheter tip & $\begin{array}{l}\text { General } \\
\text { culture* }\end{array}$ \\
\hline \multirow{2}{*}{ Neurological's disease } & 3.80 & $0.74(1.35)$ & 3.27 & - & 2.66 & - & 15.61 \\
\hline & [1.22: 11.83] & {$[0.26: 2.14]$} & {$[1.24: 8.66]$} & 0.62 & {$[0.55: 12.82]$} & 0.38 & {$[4.78: 50.98]$} \\
\hline \multirow{2}{*}{ Pneumothorax } & $0.12(8.33)$ & 1.07 & $0.79(1.27)$ & 2.02 & 1.24 & 4.17 & - \\
\hline & {$[0.03: 0.55]$} & {$[0.39: 2.99]$} & {$[0.22: 2.84]$} & {$[0.43: 9.53]$} & {$[0.15: 10.00]$} & [1.24: 13.97] & 1.00 \\
\hline \multirow{2}{*}{ Acute renal failure } & 2.58 & 5.10 & - & - & - & - & 18.06 \\
\hline & {$[0.49: 13.53]$} & [0.97 : 26.76] & 0.35 & 1.00 & 1.00 & 1.00 & {$[3.63: 89.86]$} \\
\hline \multirow{2}{*}{ Other diagnoses ** } & 1.36 & $0.78(1.28)$ & - & - & - & - & 18.06 \\
\hline & {$[0.30: 6.18]$} & {$[0.15: 4.09]$} & 0.35 & 1.00 & 1.00 & 1.00 & {$[3.63: 89.86]$} \\
\hline
\end{tabular}

: Cultures that do not allow exact isolation of a single pathogen. **: Aneurysm, Traumatic brain injury, neoplasms, immune disorders, Mileloma and exogenous poisoning

\section{Discussion}

There has been a gap in studies addressing hospital infections in the elderly in Brazil and in the world. Similar to other developing countries, in Brazil people aged 60 and older represent the fastest growing population segment. This demographic transition affects the epidemiological profile with a reduction in infectious and parasitic diseases and the increase in chronic and degenerative diseases (hypertension, renal insufficiency, diabetes mellitus, obesity, neurological and cardiovascular diseases, among others).

It is estimated that the number of elderly patients, is expected to double in the coming decades around the world especially those of older age with 85 years or more [3]. As a result of this increase, it has become common elderly patients being admitted daily the most critical services such as ICU with diagnoses ranging from a few exacerbations of chronic diseases, to the most serious health problems related to trauma and/or accidents.

In the ICU pneumonia associated with health care (PACS) is the most common infection in the general population, and usually occurs in patients intubated for more than 48 hours, causing an increase in the risk of death, prolonging the duration of mechanical ventilation and hospitalization, and increasing, too, the spending on treatment [4]. In the elderly, one should also consider changes in physiological and morphological variables that impact the various bodily functions, especially immunity, making them even more vulnerable to infections.

Pneumonia patients have a higher degree of dependence and higher rates of co-morbidities associated. Among the most common diagnosis in patients with pneumonia associated with mechanical ventilation, there is cardiovascular and neurological diseases, associated with higher severity scores (PSI IV/V: $79 \%$ vs 62\%, p <0.05 Chi- square test) [5].

The central vascular catheter in the elderly is associated with an increase in mortality in the intensive care unit for providing direct access to the bloodstream as it breaks down the natural barriers of the body. Even though little reported on studies, there is relation between the use of catheter bloodstream infection elderly [6, 7]. Of bloodstream infections, 50 to $80 \%$ are related to the use of vascular catheters [8].

Elderly patients with acute renal failure and chronic renal failure, are more likely to purchase catheters infections due to access to dialysis procedures $[9,10]$.

The study's limitations are inherent to the crosssectional design, without the possibility of monitoring of elderly people from admission to the Intensive Care Unit until the post-discharge care. Data analysis was limited to the observed variables for being consolidated in the assessment of risk factors 
for nosocomial infection of the elderly, even though there are other covariates that may be of interest to explore.

Factors associated with nosocomial infection of elderly in the Intensive Care Unit, should be identified and treated early to avoid complications that can lead to widespread infection and contribute to increased mortality of elderly in Intensive Care Units.

\section{Conclusion}

We conclude that elderly women are more exposed to wound infection. The elderly aged $70-79$ years and from other states of Brazil, are more exposed to the catheter tip infection. Having more than one preexisting comorbidity was considered a risk factor for general infection and surgical site infections. surgical procedures, trauma, neurological diseases, pneumothorax, and acute renal failure, risk factors increase the chance of developing tracheal, bloodstream infections, of surgical site, catheter tip and other infections.

\section{References}

1. Brazil, Brazilian Institute of Geography and Statistics, IBGE. Brazilian data on aging. Brasilia, 2010.

2. Schein LEC, Cesar JA. Profile of the elderly admitted into general intensive care units in Rio Grande, Southern Brazil: results of a cross-sectional survey. Rev Bras Epidemiol. 2010; 13: 289-301.

3. Marik PE. Management of the critically ill geriatric patient. Crit Care Med. 2006; 34: 176-82.

4. Boyer AF, Schoenberg $N$, Babcock $H$, McMullen KM, Micek ST, Kollef $\mathrm{MH}$. A prospective evaluation of ventilator-associated conditions and infection-related ventilator-associated conditions. CHEST. 2015; 147: 68-8.

5. Guimarães C, Santos CL, Costa F, Barata F. Pneumonia associated with health care versus community-acquired pneumonia: different entities, different approaches. Rev Port Pneumol. 2011; 17: 168-71.
6. Avci M, Ozgenc O, Coskuner SA, Olut Al. Hospital acquired infections ( $\mathrm{HAl}$ ) in the elderly: comparison with the younger patients. Arch Gerontol Geriatr. 2012; 54: 247-50.

7. Quintero ES, Toro LE, Ospina SO. Factores clínicos asociados a multirresistencia bacteriana enun hospital de cuarto nível. Infectio. 2015; 19: 161-7.

8. Curty NFR, Martins LFS, Ito CA S, Schafranski M, Brites DA, Busato CR. Morbimortality study of infection in patients undergoing different types of dialysis in a renal replacement therapy center. Braz J Infect Dis. 2014; 18: 281-6.

9. Borges PRR, Bedendo J. Risk factors associated with temporary catheter infection in patients on dialysis. Texto contexto enferm. 2015; 24: 680-5.

10. Szeto CC. Peritoneal dialysis-related infection in the older population. Perit Dial Int. 2015; 35: 659-662.

\section{Publish in International Archives of Medicine}

International Archives of Medicine is an open access journal publishing articles encompassing all aspects of medical science and clinical practice. IAM is considered a megajournal with independent sections on all areas of medicine. IAM is a really international journal with authors and board members from all around the world. The journal is widely indexed and classified Q2 in category Medicine. 